\title{
Önemli bir beraberlik: interstisyel akciğer hastalıkları ve uyku ilişkili solunum bozuklukları
}

\author{
Handan INÖNÜ KÖSEOĞLU ${ }^{1}$ \\ Asiye KANBAY ${ }^{2}$ \\ Oğuz KÖKTÜRK ${ }^{3}$
}

1 Gaziosmanpaşa Üniversitesi Tıp Fakültesi, Göğüs Hastalıkları Anabilim Dalı, Tokat, Türkiye

${ }^{1}$ Department of Chest Diseases, Faculty of Medicine, Gaziosmanpasa University, Tokat, Turkey

${ }^{2}$ Medeniyet Üniversitesi Tıp Fakültesi, Göğüs Hastalıkları Anabilim Dalı, İstanbul, Türkiye

${ }^{2}$ Department of Chest Diseases, Faculty of Medicine, Medeniyet University, Istanbul, Turkey

${ }^{3}$ Gazi Üniversitesi Tıp Fakültesi, Göğüs Hastalıkları Anabilim Dalı, Ankara, Türkiye

${ }^{3}$ Department of Chest Diseases, Faculty of Medicine, Gazi University, Ankara, Turkey

\section{ÖZET}

Önemli bir beraberlik: interstisyel akciğer hastalıkları ve uyku ilişkili solunum bozuklukları

interstisyel akciğer hastalıkları (IAH); akciğerlerde interstisyum, alveoller, küçük hava yolları ve damarları tutabilen, inflamasyon ve fibrozis gelişimi sonucu akciğer parankimini difüz olarak etkileyen, solunum yetmezliğine yol açarak ölümle sonuçlanabilen hastalıklardır. Obstrüktif uyku apne sendromu (OSAS); sistemik sonuçlarla seyreden, diğer solunum sistemi hastalıklarıla birliktelik gösterdiğinde morbidite ve mortalitesi artan bir bozukluktur. OSAS ile kronik obstrüktif akciğer hastalı̆̆ı, astım, iAH, kistik fibrozis gibi diğer akciğer hastalıklarının birlikteliği "overlap sendrom" olarak tanımlanmaktadır. OSAS'ın karakteristik özelliği olan, gece boyu tekrarlayan oksijen desatürasyonları nedeniyle, iAH-OSAS birlikteliğinde altta yatan akciğer hastalığının progresyonu hızlanmaktadır. Bu nedenledir ki, IAH'ı olgularda yaşam kalitesinin iyileştirilmesi ve hastalık progresyonunun yavaşlatılmasında eşlik eden OSAS'ın erken tanısı ve tedavisi hayati önem arz etmektedir. Bu derlemede IAH-OSAS birlikteliği çeşitli yönleriyle ele alınacaktır.

Anahtar kelimeler: Interstisyel akciğer hastalı̆̆ı, obstrüktif uyku apne sendromu, hipoksemi, solunum yetmezliği

\section{SUMMARY}

An important concomitancy: interstitial lung diseases and sleep related breathing disorders

Interstitial lung diseases (ILD), are a group of diseases which can involve pulmonary interstitium, small airways, and vessels, and diffusely affect pulmonary parenchyma as a consequence development of inflammation, and fibrosis leading to respiratory failure, and finally death. Obstructive sleep apnea syndrome (OSAS) is a disorder which courses with its systemic outcomes, and increasing morbidity, and mortality when accompanied with other respiratory system diseases. Concomitancy of OSAS with other lung diseases including chronic obstructive pulmonary disease, asthma, ILD, cystic fibrosis is termed as "overlap syndrome". Because of char-

\section{Yazışma Adresi (Address for Correspondence)}

Dr. Handan INÖNÜ KÖSEOĞLU

Gaziosmanpaşa Üniversitesi Tıp Fakültesi, Göğüs

Hastalıkları Anabilim Dalı, 60100, TOKAT - TURKEY

e-mail: handaninonu@gmail.com 
acteristic feature of OSAS ie. recurrent oxygen desaturations during night hours, ILD-OSAS concomitancy accelerates progression of underlying lung disease. Therefore, in cases with ILD, early diagnosis, and treatment of comorbid OSAS conveys vital importance in that this approach improves quality of life of the patients, and slows down progression of the disease. In this review ILD-OSAS concomitancy will be analyzed from its various aspects.

Key words: Interstitial lung disease, obstructive sleep apnea syndrome, hypoxemia, respiratory failure

\section{Gíriș}

İnterstisyel akciğer hastalıkları (IAH); akciğerlerde interstisyum, alveoller, küçük hava yolları ve damarları tutabilen, inflamasyon ve fibrozis gelişimi sonucu akciğer parankimini difüz olarak etkileyen, hipokse$\mathrm{mi}$, solunum yetmezliği, pulmoner hipertansiyon ve ölümle sonuçlanabilen, morbidite ve mortalitesi yüksek olan hastalıklardır (1).

Obstrüktif uyku apne sendromu (Obstructive sleep apnea syndrome, OSAS); erişkin erkeklerde \%3.9, kadınlarda 1.2 oranında görülen, sistemik sonuçlarla seyreden, diğer solunum sistemi hastalıklarıyla birliktelik gösterdiğinde morbidite ve mortalitesi artan bir bozukluktur $(2,3)$. OSAS ile kronik obstrüktif akciğer hastalığı (KOAH), astım, IAH, kistik fibrozis gibi diğer akciğer hastalıklarının birlikteliği "overlap sendrom" olarak tanımlanmakta, en sık OSAS-KOAH birlikteliği görülmektedir (4). Yakın tarihte üçüncü versiyonu yayınlanan uluslararası uyku bozuklukları sınıflamasında (International Classification of Sleep Disorders, ICSD-3) overlap sendrom yer almamaktadır. OSAS ICSD-3'te 2. ana başlıkta, uyku ilişkili solunum bozuklukları alt başlığı içinde; iAH yine bu ana başlık altında uyku ilişkili hipoventilasyon bozuklukları alt başığında, medikal hastalıklara bağlı uyku ilişkili hipoventilasyon grubunda yer almaktadır (Tablo 1) (5). ICSD-3'te uyku ilişkili hipoventilasyon şu şekilde tanımlanmaktadır; "parsiyel karbondioksid basıncı $\left(\mathrm{PaCO}_{2}\right)^{\prime}$ nın en az 10 dakika süreyle 55 mmHg'nın üzerinde olması veya $\mathrm{PaCO}_{2}{ }^{\prime}$ nın en az $10 \mathrm{dk}$ süreyle $50 \mathrm{mmHg}$ 'nın üzerinde olmak koşuluyla, uyanıklık değerine göre, uyku sırasında $\geq 10 \mathrm{mmHg}$ lık artış olması". Medikal hastalıklara bağlı uyku ilişkili hipoventilasyon diyebilmek içinse; hastada yukarıda tanımlanan uyku ilişkili hipoventilasyon kriteri mevcut olmalı, bu hipoventilasyon, akciğer parankim veya hava yolu hastalığı, pulmoner vasküler hastalık, göğüs duvarı bozukluğu, nörolojik bozukluk veya kas güçsüzlüğü gibi nedenlerden birine bağlı gelişmiş olmalı ve hipoventilasyon; obeziteye, ilaç kullanımına veya bilinen bir konjenital santral alveoler hipoventilasyon sendromuna bağlı olmamalıdır.
Tablo 1. AASM- Uluslararası Uyku Bozuklukları Sınıflaması (ICSD-3)

1. İnsomniler

2. Uyku ilişkili solunum bozuklukları

a) Obstrüktif uyku apne bozuklukları

b) Santral uyku apne sendromları

c) Uyku ilişkili hipoventilasyon bozuklukları

- Obezite hipoventilasyon sendromu

- Konjenital santral alveoler hipoventilasyon sendromu

- Hipotalamik disfonksiyonla birlikte geç başlangıçlı santral hipoventilasyon

- Idiyopatik santral alveoler hipoventilasyon

- ilaç ve madde kullanımına bağlı uyku ilişkili hipoventilasyon

- Medikal hastalıklara bağlı uyku ilişkili hipoventilasyon

d) Uyku ilişkili hipoksemi bozuklukları

e) İzole semptomlar ve normal varyantlar

3. Santral kaynaklı hipersomniler

4. Sirkadyen ritm (uyku/uyanıklık) bozuklukları

5. Parasomniler

6. Uyku ilişkili hareket bozuklukları

7. Diğer uyku bozuklukları

Literatürde iAH'da uykuda solunum bozuklukları (USB)'nı araştıran sınırlı sayıda çalışma bulunmakta, bu çalışmalarda IAH'da OSAS görülme oranı \%17-88 arasında bildirilmektedir (6-10). Çalışmaların çoğu idiyopatik pulmoner fibrozis (IPF)'li olgularda yapıldığı, sadece birkaç çalışmada farklı gruplardaki IAH olgularında USB araşıııldığı ve çalışmalar az sayıda olguyu içerdiği için prevalans aralığı oldukça değişken bulunmuştur.

IAH'da OSAS gelişimini açıklamaya yönelik olarak iki mekanizma ileri sürülmüştür; 1 . Akciğer volümlerinde azalma, 2. Kortikosteroid (KS)'lere bağlı obezite gelişimi.

IAH'da akciğer volümlerinde meydana gelen azalma üst hava yolu (ÜHY) stabilitesinde bozulmaya yol açmaktadır. Azalan AC volümleri, farenks üzerinde aşağı doğru genişletici kuvvetin (kaudal traksiyon) 
azalmasına yol açarak farengeal kollapsibilitenin artmasına neden olur $(11,12)$. Bu değişiklikler interkostal kaslardaki inaktivite nedeniyle, fonksiyonel rezidüel kapasitenin belirgin azalması sonucu özellikle REM döneminde görülmektedir (13-15). Bu konuda yapılan çalışmalarda akciğer fonksiyonlarındaki bozulma ile OSAS ağırlığı arasındaki ilişkiye dair çelişkili sonuçlar elde edilmiştir. IPF tanılı 18 olguda USB'nin araştırıldığı bir çalışmada AHi ile $\mathrm{FEV}_{1}$ ve FVC değerleri arasında negatif korelasyon tespit edilirken, yine iPF'li olgularda yapılan farklı bir çalışmada $\mathrm{AHI}$ ile spirometri parametrelerinin hiçbiri, akciğer volümleri, DLCO arasında ilişki gözlenmemiştir $(7,8)$. Benzer çelişkili sonuçlar farklı çalışmalarda da elde edilmiştir $(16,17)$. Araştırmacılar farklı sonuçların nedenini teknik problemlerle ilişkilendirmiş; solunum fonksiyon testi (SFT)'nin uyanık ve oturur pozisyonda yapılırken, polisomnografi (PSG)'nin uykuda ve yatar pozisyonda yapılıyor olması nedeniyle sonuçların farklı olduğunu vurgulamışlardır.

IAH'da USB gelişimini açılamaya yönelik bir diğer mekanizma; tedavide kullanılan KS'lere bağlı obezite gelişimidir. Esasında $\mathrm{IAH}^{\prime}$ da USB sıklığını araştıran çalışmalara baktığımızda, çoğu çalışmada BKi önemsenmeksizin obez olan ve olmayan tüm olguların çalışmalara dahil edildiğini görmekteyiz. Obezitenin etkisini dışlamak amacıyla, yalnızca beden kitle indeksi $(\mathrm{BKi})<30$ olan olguların dahil edildiği bir çalışmada AHI ve BKi arasında zayıf korelasyon bulunurken, obez olguların da yer aldığı bir başka çalışmada ise, OSAS tespit edilen ve edilmeyen olgularda BKi ortalamaları benzer bulunmuştur $(16,6)$. BKi normal olan IAH'lı olgularda da OSAS gelişebildiği belirtilmiştir (8). KS tedavinin etkisini ortaya koymak üzere yapılan subgrup analizinde; KS alan ve almayanlarda OSAS tanılarının, AHI ve ODi değerlerinin benzer olduğu görülmüştür (16). Bu nedenledir ki IAH'da OSAS gelişimi üzerine obezitenin etkisi hala tam bilinmemektedir.

IAH subtiplerinde OSAS sıklığına bakıldığında; yalnızca iPf'li olguların yer aldığı çalışmalarda \%88, \%61 gibi yüksek oranlar tespit edilmiştir $(7,8)$. Toplam 50 olgunun değerlendirildiği Pıhtılı ve arkadaşlarının çalışmasında; IPF tanılı 17, sarkoidoz tanılı 15, skleroderma tanılı 18 olgu çalışmada yer almış; OSAS \%82.3 ile en yüksek iPF'li olgularda görülmüştür. Bu oran sarkoidozisli olgularda \%66.6, sklerodermalı olgularda \%55.5 olarak tespit edilmiştir (16).

IAH'da görülen OSAS'ın çoğunlukla hafif dereceli olduğu, solunumsal olayların apneden ziyade hipopne ağırlıklı olduğu dikkati çekmektedir. Otuz yedi
IAH'lı (IPF, DIP, NSIP, BOOP, sarkoidoz, KDH, mesleki hastalıklar ve pnömokonyoz) olgunun değerlendirildiği Aydoğdu ve arkadaşlarının çalışmasında; hafif dereceli OSAS \%54.2, orta dereceli OSAS \%33.3, ağır dereceli OSAS \%12.5 oranında görülmüştür (6). Yine 34 iPF'li olgunun değerlendirildiği bir başka çalışmada olguların \%44'ünde hafif OSAS tespit edilmiştir (17). Pıhtılı ve arkadaşları bu oranı $\% 55.8$ tespit etmişlerdir (16). IAH'da görülen OSAS'ın daha hafif derecelerde olması; iAH'da artmış solunumsal stimülasyon nedeniyle daha az sayıda apnehipopne görülmesiyle açıklanabilir (6).

iAH'lı olgularda USB gelişmesi dışında uyku mimarisinde de değişiklikler ortaya çıkmaktadır. Toplam uyku süresi, uyku etkinliği, REM ve derin uyku süreleri genel olarak azalmış, gece içinde uyanık geçen süre artmıştır. Solunum dürtüsündeki artış ve gece öksürük atakları arousal indeksinin artmasına yol açmaktadır (6-8). Sonuçta noktürnal hipoksemi ve uyku mimari değişiklikleri bu olgularda uyku kalitesini ve yaşam kalitesini bozmaktadır $(18,19)$. IPF'de uyku ve yaşam kalitesinin değerlendirildiği prospektif bir çalışmada; 15 olgunun tamamında gün içi yorgunluk, \%20 olguda gündüz aşırı uyku hali ve yarısında insomnia semptomlarının olduğu, fiziksel ve sosyal fonksiyonlarda belirgin bozulmanın meydana geldiği tespit edilmiştir. Olgular gecenin $1 / 3$ 'ünden fazlasını desatüre geçirmiş $(<\% 90)$, yorgunluk ciddiyet skoru ile, uykudaki ortalama oksijen satürasyonu arasında belirgin korelasyon tespit edilmiştir (20).

IAH'lı olgularda uyku mimarisinde oluşan bozulma, solunumsal olaylar ve noktürnal desatürasyonlar sıklıkla REM döneminde oluşmaktadır $(7,8,17,21)$. Bu olgularda REM ilişkili OSAS görülme oranı da artmıştır $(7,8,16)$.

IAH'lı olgularda USB dışında, periyodik ekstremite hareket bozukluğu, huzursuz bacak sendromu gibi patolojilerin de görülme sıklığı artmıştır (22). IAH'lı olgularda sıkça görülen yorgunluk, bitkinlik-tükenmişlik gibi durumlar birçok faktörle ilişkilendirilse de, uyku bölünmeleri ve USB'nin bu sonuçlara katkıda bulunabileceği unutulmamalıdır. Nitekim, hastalık aktivasyon kriterlerinin hiçbirini taşımayan, sistemik tedaviye rağmen devam eden belirgin gün içi yorgunluk şikayeti olan sarkoidozlu bir olguda, PSG incelemesiyle tespit edilen OSAS'ın, pozitif hava yolu basınç ile etkin tedavisi sonrası gündüz yorgunluğun tamamen düzelmesi, mevcut durumun primer hastalıktan ziyade USB ile ilişkili olduğunun önemli bir göstergesidir (23). 
IAH ağırlı̆̆ı ile OSAS ağırlı̆̆ı arasındaki ilişkinin araştırıldığı çalışmalara bakıldığında sonuçlar farklııık arzetmektedir. Pıhtılı ve arkadaşlarının çalışmasında; IAH ağırlık indeksi difüzyon kapasitesi (DLCO) 6 dakika yürüme testi (6DYT), dispne skalası (MRC), BKi değerlerine göre olgular toplam skorlarına göre $\geq 3$ ve $<3$ olarak iki gruba ayrılmış; skoru $\geq 3$ olanlarda (hastalık ağırlığı fazla olanlar) OSAS tanısının daha yüksek olduğu ( $p=0.04)$, hastalık ağırlık skoru ile uyku etkinliği ve ortalama oksijen satürasyonunun negatif yönde, gece oksijen satürasyonunun \%90'ın altında geçtiği zaman dilimi ile pozitif yönde anlamlı ilişki gösterdiği tespit edilmiştir. i̇lave olarak difüz radyolojik tutulumu olan olgularda, AHI ve ODI'nin anlamlı yüksek olduğu görülmüştür (16). Öte yandan IAH'da klinik, radyolojik, fizyolojik parametreler ile elde edilen CRP skorunun kullanıldığı Aydoğdu ve arkadaşlarının çalışmasında, olgular CRP skoru $\geq 30$ ve $<30$ olarak iki gruba ayrılmış; $\mathrm{AHI}$, oksijenasyon, uyku mimarisi açısından gruplar arasında fark saptanmamıştır (6).

IAH-OSAS birlikteliğinde, OSAS'ın karakteristik özelliği olan gece tekrarlayıcı oksijen destürasyonları nedeniyle, pulmoner hipertansiyon ve kor pulmonale gelişimi ile hastalık progresyonu hızlanacaktır. Nitekim bir araştırmada; IPF-OSAS birlikteliği olan 44 olgunun $30(\% 68)^{\prime} u n d a$ uyanıklık oksijen satürasyonu \%94 iken ve evde oksijen tedavi endikasyonu mevcut değilken, yapılan PSG incelemesinde oksijen satürasyonunun gece \%79'a kadar düştüğü tespit edilmiştir (8). Bu noktada IPF'li olgularda gece hipoksemi varlığı rutin araştırılmalı mıdır? sorusu gündeme gelmiş ve 33 iPF tanılı olguda, SFT, oda havasında AKG analizi, 6DYT, EKO ile pulmoner arter basıncı (PAB) incelemesi ve uyku çalışması yapılmış, 33 olgunun 8 'inde $\mathrm{AHI}>5$ tespit edilmiştir. Olguların $\% 57$ 'sinde sistolik $\mathrm{PAB}^{\prime}$ ın yüksek olduğu, gece ortalama oksijen satürasyonu ile sPAB'ın negatif yönde anlamlı düzeyde ilişkili olduğu tespit edilmiştir. Yine sPAB ile, 6DYT sonrasında oksijen satürasyonunda düzelme zamanı arasında da ilişki tespit edilmiştir. Gece oksijen satürasyonu ile uyanıklık oksijen satürasyonu arasında ilişki gözlenmemiştir (24). iPF ilişkili USB'nin survi üzerine etkisinin araştırıldığı bir çalışmada; yeni tanı konulmuş ve tedavi almamış 31 iPF'li olgu ortalama 495.39 (median 530) gün takip edilmiştir (25). Olguların 12 (\%39)'sinde hafif dereceli, $16(\% 52)$ 'sında orta-ağır dereceli OSAS tespit edilmiştir. Çalışmada; uyanıklık-uykuda ölçülen $\mathrm{O}_{2}$ satürasyonu arasındaki maksimum fark (maksfark $\mathrm{SpO}_{2}$ ), gece en düşük $\mathrm{O}_{2}$ satürasyonu, klinik fonksiyonlar (survi, dispne, gündüz uykululuk), pulmoner fonksiyonlar (6DYT, kardiyopulmoner egzersiz testi-KPET) ve sağ ventrikül sistolik basıncı (RVSP) değerlendirilmiştir. Survinin, KPET'de bakılan peak $\mathrm{O}_{2}$ satürasyonu, RVSP, minimum $\mathrm{O}_{2}$ satürasyonu ile pozitif yönde, maksfark $\mathrm{O}_{2}$ satürasyonu ile negatif yönde anlamlı ilişkili olduğu görülmüş, AHI tüm çalışma grubu incelendiğinde sağkalımla ilişkili bulunmazken, CPAP tedavisi alanlar dışlandığında AHI'nin azalmış sağkaIımla ilişkili olduğu tespit edilmiştir. Sonuç olarak, uykuda görülen intermittan desatürasyonların iPF'li olgularda sağkalımı etkilediği gösterilmiştir.

Çeşitli etyolojilere bağlı PH tanılı 28 olguya (\%78'inin fonksiyonel klasifikasyonu class II-III olan) yapılan PSG incelemesinde; olguların \%50'sinde $\mathrm{AHI} \geq 5$ (ortalama AHi: $11.4 \pm 19.8$ ) olduğu, ortalama $\mathrm{PAB}$ ile, AHI ve gece oksijen satürasyonunun $<\% 90$ geçtiği zaman yüzdesi arasında anlamlı ilişki olduğu görülmüştür (26). ¿̇AH'da solunum dürtüsü arttığı için, hipoventilasyonun hastalığın ileri dönemlerinde gelişmesi beklenir, ancak solunum kontrolü bozulmuş olanlarda erken dönemde de görülebilir (27).

IAH'larının OSAS gelişimindeki rolü ne kadar önemliyse, OSAS'ın IAH gelişimi veya progresyonuna katkısı da bir o kadar önemlidir. OSAS'ın majör karakteristiği olan gece boyu tekrarlayan hipoksemireoksijenasyon epizodları, iskemi-reperfüzyon hasarına benzer şekilde oksidatif streste artışa, serbest oksijen radikallerinin oluşumuna ve inflamasyona neden olmaktadır (28). Bu inflamatuvar olaylar dizisi; dolaşımda inflamatuvar mediyatör artışı ile akciğerlerde subklinik düzeyde bir hasara neden olabilir. Nitekim hayvan çalışmalarında tıpkı OSAS'da olduğu gibi, inspiratuar rezistif yükteki artışın alveoler hasara yol açabileceği gösterilmiştir (29). OSAS'da kapalı glotise karşı gerçekleşen zorlu inspirasyon muhtemelen; interstisyumda basınç azalmasına neden olarak alveoler deformasyon ve kapiller düzeyde proinflamatuvar yanıtla sonuçlanmaktadır (30). Yine OSAS'da sık görülen gastroözefageal reflü, patogenezinde önemli rol oynadığı iPF'nin gelişimi ve progresyonu için de risk teşkil etmektedir.

Bu bilgiler ışığında, IAH olan hastalarda OSAS ve ilişkili semptomlar mevcut ise, uyanıklık kan gazı değerleri normal olmasına rağmen pulmoner hipertansiyon-kor pulmonale gelişmişse, hastalık aktivasyonu yokken veya tedaviye iyi yanıt alınmasına rağmen ısrarlı yorgunluk-bitkinlik semptomları varsa PSG yapılarak OSAS varlığının araştırılması uygun bir yaklaşım olacaktır.

Sonuçta; IPF gibi günümüzde halen etkin bir tedavisi olmayan IAH tiplerinde yaşam kalitesinin iyileştirilmesi ve hastalık progresyonunun yavaşlatılması 
öncelikli hedeftir. Bu nedenledir ki; IAH'ye eşlik eden OSAS gibi komorbid durumların erken tanısı ve tedavisi hayati önem arz etmektedir.

\section{ÇIKAR ÇATIŞMASI}

Bildirilmemiştir.

\section{KAYNAKLAR}

1. Berkoğlu M, Başay N. Tanım, sınıflandırma ve epidemiyoloji. Erdoğan Y, Samurkaşoğlu B (editörler). Interstisyel Akciğer Hastalıkları Genel Yaklaşım. Ankara: Güneş Kitabevi, 2002:1-11.

2. Bixler EO, Vgontzas AN, Lin HM, Ten Have T, Rein J, VelaBueno A, et al. Prevalence of sleep disorders breathing in women: effects of gender. Am J Respir Crit Care Med 2001; 163:608-13.

3. Rasche $K$, Orth M. Sleep and breathing in idiopathic pulmonary fibrosis. J Physiol Pharmacol 2009;5:13-4.

4. Köktürk O, Çiftçi B. Overlap sendromu. Tüberk Toraks 2003;51:333-48.

5. American Academy of Sleep Medicine: International classification of sleep disorders (ICSD) Third edition, 2014.

6. Aydogdu M, Ciftci B, Guven S, Ulukavak CT, Erdogan Y. Assessment of sleep with polysomnography in patients with interstitial lung disease. Tuberk Toraks 2006;54:213-21.

7. Mermigkis C, Chapman J, Golish J, Mermigkis D, Budur K, Kopanakis $A$, et al. Sleep-related breathing disorders in patients with Idiopathic pulmonary fibrosis. Lung 2007; 185:173-8.

8. Lancaster LH, Mason WR, Parnell JA, Rice TW, Loyd JE, Milstone $A P$, et al. Obstructive sleep apnea is common in idiopathic pulmonary fibrosis. Chest 2009;136:772-78.

9. Bye PT, Issa F, Berthon-Jones M, Sullivan CE. Studies of oxygenation during sleep in patients with interstitial lung diseases. Am Rev Respir Dis 1984;129:27-32.

10. Turner GA, Lower EE, Corser BC, Gunther KL, Baughman $R P$. Sleep apnea in sarcoidosis. Sarcoidosis Vasc Diffuse Lung Dis 1997; 14:61-4.

11. Tagaito $Y$, Isono S, Remmers JE, Tanaka A, Nishino T. Lung volume and collapsibility of the passive pharynx in patients with sleep-disordered breathing. I Appl Phsiol 2007; 103:1379-85.

12. Zammit C, Liddicoat H, Moonsie I, Makker H. Obesity and respiratory diseases. Int J Gen Med 2010;3:335-43.

13. Bradley TD, Brown IG, Grossman RF, Zamel N, Martinez $D$, Phillipson EA, et al. Pharyngeal size in snorers, nonsnorers, and patients with obstructive sleep apnea. N Engl J Med 1986;315:1327-31.

14. Sériès F, Cormier $Y$, Lampron N, La Forge J. Increasing the functional residual capacity may reverse obstructive sleep apnea. Sleep 1988;11:349-53.

15. Schory K, White DP. Lung volume and continuous positive airway pressure requirements in obstructive sleep apnea. Am J Respir Crit Care Med 2005;172:114-7.
16. Pihtili A, Bingol Z, Kiyan E, Cuhadaroglu C, Issever $H$, Gulbaran Z. Obstructive sleep apnea is common in patients with interstitial lung disease. Sleep Breath 2013;17:1281-8.

17. Mermigkis C, Stagaki E, Tryfon S, Schiza S, Amfilochiou A, Polychronopoulos $V$, et al. How common is sleep-disordered breathing in patients with idiopathic pulmonary fibrosis? Sleep Breath 2010;14:387-90.

18. Clark M, Cooper B, Singh S, Cooper M, Carr A, Hubbard $R$. A survey of nocturnal hypoxaemia and health related quality of life in patients with cryptogenic fibrosing alveolitis. Thorax 2001;56:482-86.

19. Krishnan V, McCormack MC, Mathai SC, Agarwal S, Richardson B, Horton MR, et al. Sleep quality and healthrelated quality of life in idiopathic pulmonary fibrosis. Chest 2008;134:693-98.

20. Mermigkis C, Stagaki E, Amfilochiou A, Polychronopoulos $V$, Korkonikitas $P$, Mermigkis $D$, et al. Sleep quality and associated daytime consequences in patients with idiopathic pulmonary fibrosis. Med Princ Pract 2009;18:10-5.

21. Aronson RM, Carley DW, Onal E, Wilborn J, Lopata M. Upper airway muscle activity and thoracic volume dependence of upper airway resistance. I Appl Physiol 1991;70:430-38.

22. Prado G, Allen R, Trevisani V, Toscano V, Earley C. Sleep disruption in systemic sclerosis (scleroderma) patients: clinicaland polysomnographic findings. Sleep Med 2002;2: 341-45.

23. Drent $M$, Verbraecken J, van der Grinten C, Wouters E. Fatigue associated with obstructive sleep apnea in a patient withsarcoidosis. Respiration 2000;67:337-40.

24. Pitsiou G, Bagalas V, Boutou A, Stanopoulos I, Argyropoulou-Pataka P. Should we routinely screen patients with idiopathic pulmonary fibrosis for nocturnal hypoxemia? Sleep Breath 2013;17:447-8.

25. Kolilekas L, Manali E, Vlami KA, Lyberopoulos $P$, Triantafillidou C, Kagouridis K, et al. Sleep oxygen desaturation predicts survival in idiopathic pulmonary fibrosis. J Clin Sleep Med 2013;9:593-601.

26. Prisco DL, Sica AL, Talwar A, Narasimhan M, Omonuwa K, Hakimisefat $B$, et al. Correlation of pulmonary hypertension severity with metrics of comorbid sleep-disordered breathing. Sleep Breath 2011;15:633-9.

27. Shea SA, Winning Al, McKenzie E, Guz A. Does the abnormal pattern of breathing in patients with interstitial lung disease persist in deep, non-rapid eye movement sleep? Am Rev Respir Dis 1989;39:653-58.

28. Takama N, Kurabayasi M. Influence of untreated sleep disordered breathing on the longterm prognosis of patients with cardiovascular disease. Am J Cardiol 2009;103:730-34.

29. Toumpanakis D, Kastis GA, Zacharatos P, Sigala I, Michailidou $T$, Kouvela $M$, et al. Inspiratory resistive breathing induces acute lung injury. Am J Respir Crit Care Med 2010;182:1129-36.

30. Lederer DI, Jelic S, Bhattacharya J, Basner RC. Is obstructive sleep apnea a cause of idiopathic pulmonary fibrosis? Arch Pathol Lab Med 2012;136:470. 